\title{
NET Blood Transcript Analysis Defines the Crossing of the Clinical Rubicon: When Stable Disease Becomes Progressive
}

\author{
Marianne Pavel $^{\mathrm{a}}$ Henning Jann $^{\mathrm{a}}$ Vikas Prasad $^{\mathrm{b}}$ Ignat Drozdov ${ }^{\mathrm{c}}$ \\ Irvin M. Modlin ${ }^{c}$ Mark Kidd ${ }^{c}$ \\ ${ }^{a}$ Department of Hepatology and Gastroenterology, Campus-Virchow-Klinikum, and ${ }^{\mathrm{b}}$ Department of Nuclear \\ Medicine, Charité Universitätsmedizin, Berlin, Germany; ${ }^{\complement}$ Wren Laboratories, Branford, Conn., USA
}

\author{
Key Words \\ Biomarker · Carcinoids · Chromogranin · Multianalyte . \\ Neuroendocrine tumor $\cdot$ NETest . Polymerase chain reaction . \\ Prognostic · Transcript
}

\begin{abstract}
Background/Aims: A key issue in gastroenteropancreatic neuroendocrine tumors (GEP-NETs) is early identification and prediction of disease progression. Clinical evaluation and imaging are limited due to the lack of sensitivity and disease indolence. We assessed the NETest as a predictive and prognostic marker of progression in a long-term follow-up study. Methods: GEP-NETs $(n=34)$ followed for a median 4 years (2.2-5.4) were evaluated. WHO tumor grade/stage grade $1: n=17$, grade $2: n=14$, grade $3: n=1$ (for 2 , no grade was available); 31 (91\%) were stage IV. Baseline and longitudinal imaging and blood biomarkers were available in all, and progression was defined per standard clinical protocols (RECIST 1.0). The NETest was measured by quantitative PCR of blood and multianalyte algorithmic analysis (disease activity scaled $0-100 \%$ with low $<40 \%$ and high activity risk cutoffs $>80 \%$ ); chromogranin A ( $\mathrm{CgA})$ was measured by radioimmunoassay (normal $<150 \mu \mathrm{g} / \mathrm{l}$ ); progression-free survival (PFS) was analyzed by Cox proportional-hazard regression and Kaplan-Meier analysis. Results: At baseline, 100\% were NETest positive, and CgA was elevated in $50 \%$. The only
\end{abstract}

baseline variable (Cox modeling) associated with PFS was NETest (hazard ratio $=1.022,95 \%$ confidence interval $=$ $1.005-1.04 ; p<0.012)$. Using Kaplan-Meier analyses, the baseline NETest $(>80 \%)$ was significantly associated $(p=$ 0.01 ) with disease progression (median PFS 0.68 vs. 2.78 years with $<40 \%$ levels). The NETest was more informative (96\%) than $\mathrm{CgA}$ changes $(\geq 25 \%)$ in consistently predicting disease alterations $\left(40 \%, p<2 \times 10^{-5}, x^{2}=18\right)$. The NETest had an earlier time point change than imaging (1.02 \pm 0.15 years). Baseline NETest levels $>40 \%$ in stable disease were $100 \%$ prognostic of disease progression versus $\mathrm{CgA}\left(\mathrm{X}^{2}=5\right.$, $p<0.03)$. Baseline NETest values $<40 \%$ accurately $(100 \%)$ predicted stability over 5 years $\left(p=0.05, x^{2}=3.8\right.$ vs. CgA). Conclusion: The NETest correlated with a well-differentiated GEP-NET clinical status. The NETest has predictive and prognostic utility for GEP-NETs identifying clinically actionable alterations $\sim 1$ year before image-based evidence of progression.

๑ 2016 S. Karger AG, Basel

\section{Introduction}

Over the last decade, sustainable and demonstrably effective clinical advances in the management of gastroenteropancreatic neuroendocrine tumor (GEP-NET) disease have included a well-defined classification system,

\section{KARGER}

(C) 2016 S. Karger AG, Basel

E-Mail karger@karger.com

www.karger.com/nen 
introduction of novel therapeutic agents, imaging advances and multidisciplinary strategies to coordinate management [1-4]. Similarly, an appreciation of the limitations of support for neuroendocrine oncology has escalated attention in what was previously a clinically and scientifically underserved disease process [5]. Despite this, there remain two critical areas that limit advances. The first is the relative paucity of knowledge in respect of the molecular and mechanistic basis of the disease [6]. The second is the difficulty in accurately identifying alterations in the disease state from an indolent biology or stability to a progressive or a micrometastatic phenotype.

GEP-NET assessment is currently represented by an amalgam of clinical judgment, imaging and, to a lesser extent, biomarker measurement [7]. Irrespective of clinical astuteness, the often indolent nature of the disease, the limitations of imaging and the absence of credible biomarkers hinders the identification of disease evolution and presents a challenging management obstacle. Disease progression and recurrence or therapeutic responses are usually defined using a combination of anatomical and functional imaging superimposed upon alterations in symptoms or perturbations in biomarkers [7]. Anatomical imaging using the Response Evaluation Criteria in Solid Tumors (RECIST) criteria, however, exhibits welldocumented limitations in NETs [8-10]. Functional imaging with somatostatin receptor-based strategies, e.g. ${ }^{68} \mathrm{Ga}$-somatostatin analog (SSA) PET/CT, is of value [11] but resolution sensitivity ( 5-6 $\mathrm{mm}$ ) and partial volume effects limit the ability to detect small changes in tumors; the discriminant index of progression is below an effective management threshold $[12,13]$. FDG-PET, though providing useful predictive clinical information, is not established as an early harbinger of disease progression [14]. Current imaging strategies in NETs therefore remain suboptimal $[15,16]$.

Although biomarkers are used in conjunction with imaging as accessories for clinical decision-making, 'biochemical' responses are nonconcordant with imagebased assessments [1]. This is particularly disappointing since information is readily accessible from blood or urine without either the complexities and limitations of imaging or the risks of invasive and repetitive tissue sampling [17]. To date, identification of an exemplary biomarker(s) in NET oncology has eluded disease stakeholders because of a reliance on monoanalytes, limitations in technology or a lack of understanding of the molecular basis of the disease. Candidates have proven to be insensitive, nonspecific or, if accurate, of perfunctory usage in only one disease (e.g. gastrin, insulin) [18].

Prognostic Utility of the NETest
Chromogranin A (CgA) represents the best-described biomarker but its limitations in terms of assay reproducibility, sensitivity and specificity have been extensively documented with resultant clinical skepticism as to its utility [19]. Other disciplines of oncology have gravitated to the conclusion that exocytotic or protein products fail to capture the biology of a neoplastic cell and that a dynamic and panoramic view of an evolving neoplasm can best be captured by a multidimensional assessment of the cell's molecular genomic machinery. This strategy rejects the concept that a monoanalyte measurement shows accurate biomarkers since its unidimensionality cannot mathematically encompass the diversity of the neoplastic environment. Multiple analyte measurements and mathematical algorithmic analyses that accurately capture the magnitude of the biological information [20] provide the basis for acceptable biomarker strategies [21].

In GEP-NET disease, circulating tumor cells, microRNA levels and circulating transcript analysis have been evaluated. The former represents an intriguing nascent technology but current methodological limitations hinder clinical applicability, though considerable potential remains to be assessed pending the development of single cell genomic analysis [22]. MicroRNA measurement is of interest though confounding factors are disease specificity and the immense heterogeneity of the molecules and their proxies [23]. Currently, the most widely investigated biomarker tool is represented by bloodbased multianalyte transcript analysis [24, 25]. Blood gene expression closely correlates with tumor tissue expression levels, and inferential gene analysis of relevant clusters captures the biology of neuroendocrine neoplasia facilitating the accurate definition of clinical status [26].

The multianalyte-derived NET gene signature encompasses the expression of 51 genes assessed by 4 different prediction algorithms. This is then scaled to a disease/ tumor activity (0-100\%) score [26], using expressions that specifically capture the hallmarks of neoplasia [27], and may be used to provide direct information about the tumor, its pathophysiology, and its state of evolution from stability to progression. To assess this, we prospectively collected blood samples from NET disease patients at a single center (ENETS Center of Excellence - Charité, Berlin) over a $\sim 5$-year time period and appraised the utility of biomarkers and imaging in defining the bandwidth of the disease spectrum that embraces that most critical clinical decision-making fulcrum: when stability and disease remission become progression. 


\section{Materials and Methods}

\section{Patients}

Thirty-four GEP-NETs (collected between May and October 2009) were histopathologically confirmed as well differentiated $(\mathrm{n}=31$; grade 1 or 2$), 1$ was grade 3 , and 2 were not available when studied. Patient demographics are summarized in table 1. Thirtyone had radiologically demonstrable disease (stage IV), ascertained within 6 months prior to study initiation; 3 exhibited no evidence of disease. All patients provided informed consent for the blood translational analysis authorized by the local ethics committee (authorization EA2_064_09). Patients were followed up for a median of 4 years (2.2-5.4 years), and imaging was undertaken as dictated by their clinical condition and response to therapy.

\section{Blood Sampling Schedule}

Whole blood $(10 \mathrm{ml})$ for transcript analysis was collected at baseline and thereafter at clinically defined points during the follow-up. Plasma for CgA analysis was obtained at exactly the same time points. Overall, blood samples were collected a median 2.5 times per patient (range: $2-5$ ).

\section{Image Analysis}

Anatomical imaging (CT/MRI) was used to evaluate patients at study entry and at appropriate time intervals until progression occurred. RECIST 1.0 criteria were used to assess therapy response. The consensus for the therapeutic response as stable disease (including partial response or complete remission, CR) or disease progression during follow-up was confirmed by a NET Tumor Board Group (M.P., H.J., V.P.). Staging was undertaken a median 7 times per patient (range: $3-15$ ).

\section{PCR-Based Transcript Analysis NETest}

The NETest assesses biological activity using gene inference technology and cancer hallmark prediction [26]. Details of the PCR methodology, mathematical analysis and validation have been published in detail $[24,26,28,29]$. The procedure utilizes a 2 -step protocol (RNA isolation, cDNA production and PCR) [24, 28] from EDTA-collected whole blood [24, 28]. The expression of 51 NET marker genes includes analysis of clusters of biologically relevant genes that constitute the different 'omes' (SSTRome, proliferome, metabolome, secretome, epigenome and pluromes) [26] which define the NET 'fingerprint'. Expression was normalized to housekeepers and quantified versus a population control [24]. Multianalyte algorithm analysis was undertaken (support vector machine, linear discriminant analysis, K-nearest neighbor, and Bayes classifier) for categorization into different groups using the 'majority vote' [24]. This results in a $0-8$ score $[24,28]$ which is converted to an activity ranging from 0 (low activity) to $100 \%$ (high activity) based on the expression of 'omic' genes [26]. Elevated expression of these genes is used to weight the score such that a high score, e.g. ' 8 ', when combined with elevated 'omes' (identified to differentiate progressive disease, $\mathrm{PD}$, from stable disease [26]) is scaled to $100 \%$ (high activity). A score of ' 8 ' with a low 'ome' is weighted to $53 \%$. We determined the ranges that conform to clinical disease assessment: minimal activity $=<0-14 \%$, low activity $=$ $14-40 \%$, and intermediate-high activity $=>40-100 \%$ [26]. In this study, we used $\geq 80 \%$ as a cutoff for progressive disease, i.e. a NETest score of $80-100 \%$ as indicative of highly active disease. This has previously been used as a cutoff to predict disease progres-
Table 1. Patient demographics

\begin{tabular}{|c|c|}
\hline Characteristic & Entire cohort $(\mathrm{n}=34)$ \\
\hline Mean age, years & $60.2(43-83)$ \\
\hline Gender (M:F) & $17: 17$ \\
\hline \multicolumn{2}{|l|}{ Grade } \\
\hline 1 & 17 \\
\hline 2 & 14 \\
\hline 3 & 1 \\
\hline Unknown & 2 \\
\hline \multicolumn{2}{|l|}{ Site } \\
\hline Gut & 25 \\
\hline Pancreas & 9 \\
\hline \multicolumn{2}{|l|}{ Stage } \\
\hline $\mathrm{CR}^{1}$ & 3 \\
\hline Stage IV & 31 \\
\hline \multicolumn{2}{|l|}{ Status } \\
\hline Stable & 18 \\
\hline Progressive & 9 \\
\hline Disease free & 3 \\
\hline Partial remission & 1 \\
\hline Disease status not known & 3 \\
\hline \multicolumn{2}{|l|}{ Treatment at T0 } \\
\hline None & 14 \\
\hline SSA & 16 \\
\hline SSA + everolimus & 1 \\
\hline STZ/5-FU & 3 \\
\hline \multicolumn{2}{|l|}{ Treatment during study } \\
\hline Everolimus & 7 \\
\hline PRRT & 5 \\
\hline TEMCAP & 4 \\
\hline STZ/5-FU & 2 \\
\hline Surgery & 2 \\
\hline Sunitinib & 1 \\
\hline Telotristat etiprate & 1 \\
\hline TAE & 1 \\
\hline Median baseline $\operatorname{CgA}, \mu \mathrm{g} / \mathrm{l}$ & $157(67-58,600)$ \\
\hline Median baseline NETest, \% & $40(6.7-93.4)$ \\
\hline
\end{tabular}

Figures in parentheses indicate ranges. $\mathrm{CR}=$ Complete remission; $\mathrm{T} 0$ = time of first blood sample; $\mathrm{STZ}=$ streptozotocin; 5 -FU $=5$-fluorouracil; $\mathrm{PRRT}=$ peptide receptor radionuclide therapy; TEMCAP = temozolomide + capecitabine; $\mathrm{TAE}=$ transarterial embolization.

${ }^{1}$ Three patients were not included in the group analysis: 45 years old, F, grade 1, duodenum, surgery (disease-free for entirety of study); 69 years old, M, grade 1, duodenum, surgery (diseasefree for entirety of study); 63 years old, $M$, grade 3, pancreas, surgery (disease-free at start but recurrence at 2.2 years).

sion in SSA-treated patients [29]. We also evaluated a lower value $(\geq 70 \%)$ to assess whether this would function as a more effective/ sensitive predictor of disease progression. This is based on a preliminary affinity propagation algorithm analysis [30] undertaken on the sample set that identified a value $\geq 70 \%$ to be informative for predicting disease progression. 
CgA Assay

Serum CgA was measured using a competitive radioimmunoassay (CGA-RIACT, Cisbio Bioassays) [31]. This is a solid-phase 2-site immunoradiometric assay; two monoclonal antibodies are used against sterically remote sites on CgA. The assay can detect whole and fragmentary CgA species and is a standard assay at the Charité. The reference range was $19-150 \mu \mathrm{g} / \mathrm{l} ; 150 \mu \mathrm{g} / \mathrm{l}$ was used to define the upper limit of normal (ULN). Values $>150 \mu \mathrm{g} / \mathrm{l}$ signified an elevated $\mathrm{CgA}$, while values $\geq 300 \mu \mathrm{g} / \mathrm{l}(2 \times \mathrm{ULN})$ were used to signify abnormally elevated CgA [32]. In subjects with elevated $\mathrm{CgA}$, an increase $\geq 25 \%$ between any two time points was used as a measure to predict disease progression. This is based on a previous retrospective study which found that this value exhibited a sensitivity and specificity of $>85 \%$ for predicting disease progression during patient monitoring [33].

\section{Grading}

Tumors were graded $(1,2$, or 3$)$ according to the WHO classification, utilizing the Ki-67 values obtained from the original histopathological reports [34].

\section{Statistical Analyses}

Analyses included $\chi^{2}$ (Fisher's, 2-tailed), nonparametric (Mann-Whitney, 2-tailed) measurements, Kaplan-Meier survival curves (progression-free survival, PFS), event curve analysis (based on Kaplan-Meier curves), and multivariate analysis (Cox proportional-hazard regression). Prism 6.0 for Windows (GraphPad Software, La Jolla Calif., USA; www.graphpad.com) and MedCalc Statistical Software version 16.2.1 (MedCalc Software bvba, Ostend, Belgium; http://www.medcalc.org; 2013) were utilized. PFS of the cohort over the extent of the study (i.e. time from baseline to image-verified disease progression) was assessed to provide a descriptive overview of the cohort. The utility of baseline biomarkers for predicting PFS based on imaging (RECIST) was examined at two different time points (baseline $=$ time 0 and Time $1=$ a subsequent follow-up time when the majority of the patients, i.e. $n=29$, had blood sample collections). For NETest predictive accuracy assessment, cutoffs of 70 and $80 \%$ were evaluated. CgA levels $>150$ and $\geq 300 \mu \mathrm{g} / \mathrm{l}(2 \times \mathrm{ULN})$ were evaluated. For the event curve analyses, the time difference between a blood sample and image-based evidence for disease progression was identified. For individual biomarkers, the data are presented as means \pm SEM.

\section{Results}

\section{Patient Demographics}

Thirty-four patients (stable $\mathrm{n}=18,53 \% ; \mathrm{PD} \mathrm{n}=9,26 \%$; disease free on CT/MRI, i.e. $\mathrm{CR}, \mathrm{n}=3,9 \%$; partial remission $\mathrm{n}=1,3 \%$; disease status not known $\mathrm{n}=3,9 \%$ ) were included (table 1). Disease types included small intestine $(\mathrm{n}=24)$, pancreas $(\mathrm{n}=7), 2$ multiple endocrine neoplasia/ Zollinger-Ellison syndrome and 1 cancer of unknown primary. Most cases were TNM stage IV (31/34), and 3 were CR (no evidence of disease on CT/MRI) following (curative) surgery. Subjects were a median 57 years old at the time of enrollment (range 43-83 years) with a similar gen- der ratio of M:F 17:17. The WHO grading distribution was grade $1=17$, grade $2=14$, grade $3=1$, while 2 had no grade available. Previous therapy included surgery $(\mathrm{n}=$ 23), SSAs $(n=9)$ and streptozotocin/5-fluorouracil $(n=2)$. At enrollment, 16 were receiving SSAs, 1 a combination of SSA and everolimus, 3 streptozotocin/5-fluorouracil and 14 were not being treated. Treatment modalities thereafter involved use of everolimus $(\mathrm{n}=7)$, peptide receptor radionuclide therapy $(\mathrm{n}=5)$, temozolomide + capecitabine $(\mathrm{n}=4)$, streptozotocin/5-fluorouracil $(\mathrm{n}=2)$, sunitinib $(\mathrm{n}=1)$ or telotristat etiprate $(\mathrm{n}=1)$. Two patients received surgery; 1 received transarterial embolization. These were all undertaken after disease progression had been identified (typically 2-3 years into the study). These patients were not excluded from the group analysis because blood samples had already been collected prior to this therapy. After a median 4.4-year (range 2.2-5.4) observation period, 27 were alive, 5 were lost to follow-up and 2 had died.

Two were excluded from group analysis because they had CR and remained thus for the duration of the study (patient 15, with Zollinger-Ellison syndrome/duodenum, $<1 \%$, surgery: 4.8 years; patient 21 , with duodenum, $<1 \%$, surgery: 3.2 years). A third patient was also excluded due to $\mathrm{CR}$ at the start of the study (patient 26, pancreas, $30 \%$, surgery: 2.2 years before disease recurrence).

The median PFS for the patient cohort $(\mathrm{n}=31)$ was 2.59 years. Patients with $\mathrm{PD}(\mathrm{n}=7, \mathrm{PD}$ and mixed progression: $\mathrm{n}=2$ ) had a lower median survival, 0.7 years, than those with stable disease (i.e. stable disease, partial response and not known; 2.7 years, $p=0.11$; fig. 1a). Grade was not related to PFS. Disease site influenced PFS (fig. 1b), with pancreatic tumors exhibiting a PFS of 1.84 years compared to 3.67 years for gastrointestinal NETs $(p=0.27)$.

\section{Baseline Biomarker Parameters}

CR Patients $(\mathrm{n}=3)$

The baseline NETest for the 2 patients who were surgically 'cured' was 27 and 14\%, while CgA was 343 and 381 $\mu \mathrm{g} / \mathrm{l}$, respectively. Two sequential measurements at 2.6 and 3.9 years (in patient 15) were 33 and 33\%; CgA was $95 \mu \mathrm{g} / \mathrm{l}$. For patient 21, the NETest at 3.2 years was $20 \%$, $\mathrm{CgA}$ was $248 \mu \mathrm{g} / \mathrm{l}$. The third patient developed recurrence after 2.2 years. This was a grade $3(\mathrm{Ki}-67=30 \%)$ pancreatic NET. The NETest was $14 \%$ at baseline, and the $\mathrm{CgA}$ level was $83.1 \mu \mathrm{g} / \mathrm{l}$. The subsequent NETest level was $66.7 \%$ when disease recurrence was noted. CgA was normal $(95 \mu \mathrm{g} / \mathrm{l})$. An additional measurement was lower (NETest 40\%; CgA $124 \mu \mathrm{g} / \mathrm{l}$ ) when the disease was adequately treated with temozolomide + capecitabine (RECIST - stable). 


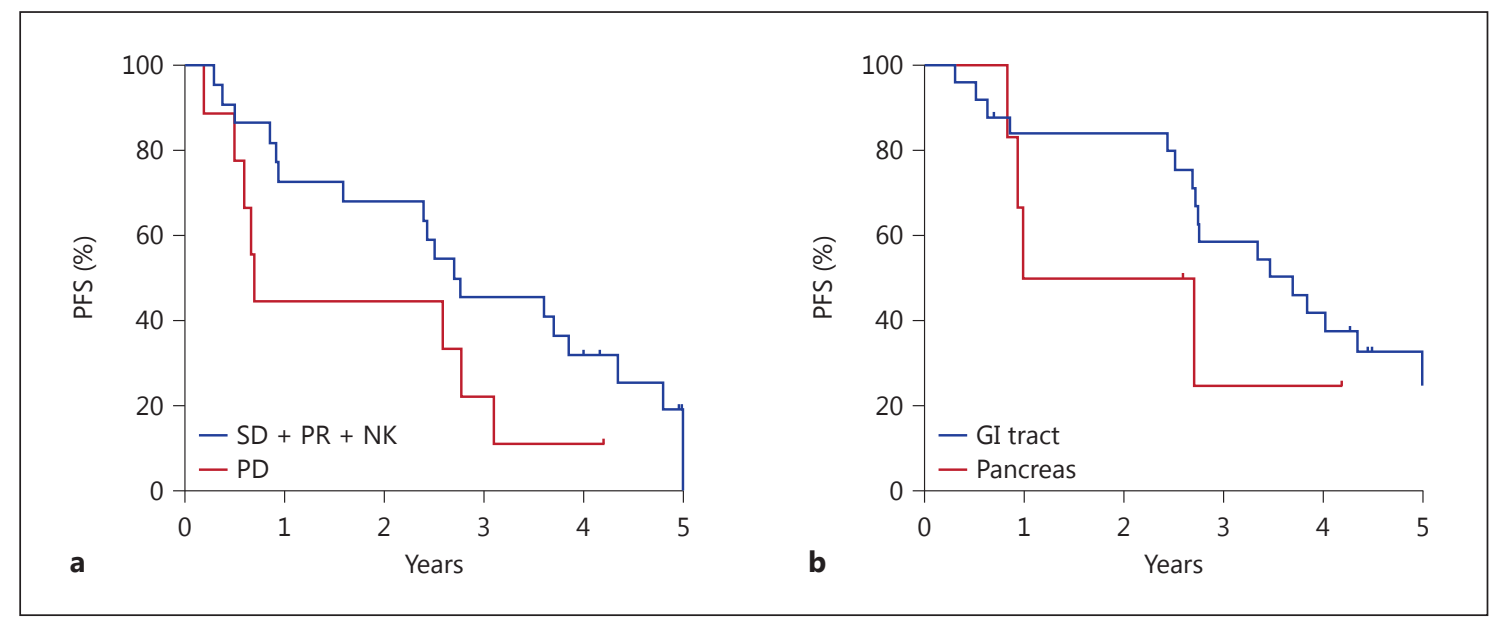

Fig. 1. PFS in the cohort $(n=31)$. a Groups defined by imaging had PD at baseline $(n=9)$ compared to those with stable disease (SD) or identified as partial response (PR) to therapy. The 3 patients who were undefined (not known: NK) were included in the stable disease group. The median PFS was 0.7 years in the PD group versus 2.71 years $(\mathrm{p}=0.11)$. $\mathbf{b}$ PFS assessed by tumor site. Pancreatic NETs had a PFS of 1.84 years compared to gastrointestinal (GI) tract tumors with 3.70 years $(\mathrm{p}=0.27)$.
Fig. 2. Baseline blood-based biomarker expression $(\mathrm{n}=31)$. a Groups had PD at baseline $(n=9)$ or stable disease $(S D ; n=22)$. CgA levels tended $(\mathrm{p}=0.12)$ to be higher in the PD group at baseline. Means \pm SEM. b NETest levels were significantly elevated in the PD group at baseline $(\mathrm{p}<0.05)$. Means \pm SEM.

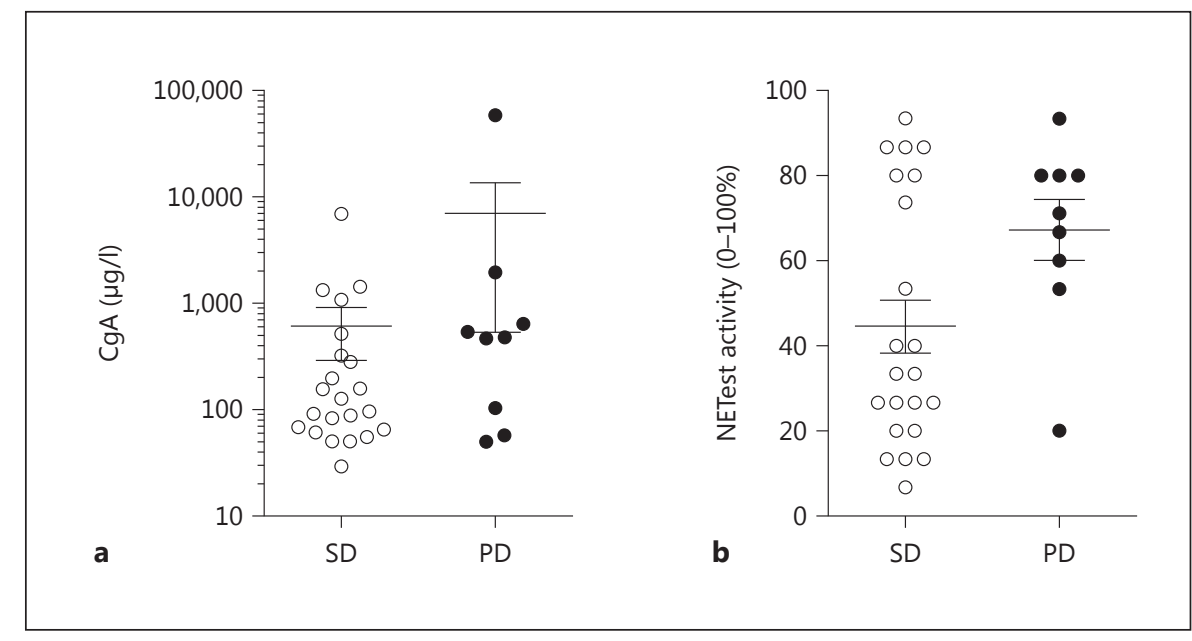

Total CgA Levels $(\mathrm{n}=34)$

At baseline, $\mathrm{CgA}$ was $2,261 \pm 1,720 \mu \mathrm{g} / \mathrm{l}$. Levels were higher in pancreatic NETs $(9,935 \pm 8,160 \mu \mathrm{g} / \mathrm{l})$ than gut NETs $(313 \pm 77 \mu \mathrm{g} / \mathrm{l}, \mathrm{p}<0.006)$, were increased in grade 2 versus grade $1(4,767 \pm 4,144$ vs. $591 \pm 378 \mu \mathrm{g} / \mathrm{l}, \mathrm{p}<0.05)$ but were not different by stage (stage IV vs. CR: 2,617 \pm 2,014 vs. $495 \pm 184 \mu \mathrm{g} / \mathrm{l}, \mathrm{p}=$ n.s.).

CgA Levels in the Patient Cohort $(\mathrm{n}=31)$

Levels tended to be higher in PD (6,989 $\pm 6,454$ vs. 603 $\pm 315 \mu \mathrm{g} / \mathrm{l}, \mathrm{p}=0.12$, fig. $2 \mathrm{a})$. Sixteen (50\%) exhibited elevated (above the ULN $=150 \mu \mathrm{g} / \mathrm{l}$ ) CgA levels. Twelve of the $16(75 \%)$ had a baseline $\mathrm{CgA} \geq 300 \mu \mathrm{g} / \mathrm{l}$. Elevated CgA was not associated $(\mathrm{p}=0.26)$ with the eventual development of progressive disease compared to normal levels (fig. 3a). Abnormally high $\mathrm{CgA}(\geq 300 \mu \mathrm{g} / \mathrm{l})$ was not associated with outcome either, although a shorter median survival was noted (1.24 vs. 2.76 years).

Total NETest $(\mathrm{n}=34)$

At baseline, the NETest was $48.4 \pm 5 \%$. Levels were not different between sites (pancreatic NETs: $57.8 \pm 7.3 \%$ vs. gut NETs: $42.7 \pm 5.9 \%, \mathrm{p}=0.28$ ) or grade (grade $1: 45.3 \pm$ $7 \%$ vs. grade 2: $47 \pm 7 \%, \mathrm{p}=$ n.s.) but were different by stage (stage IV vs. CR: $48.7 \pm 5$ vs. $16 \pm 6 \%, p=0.05$ ). 


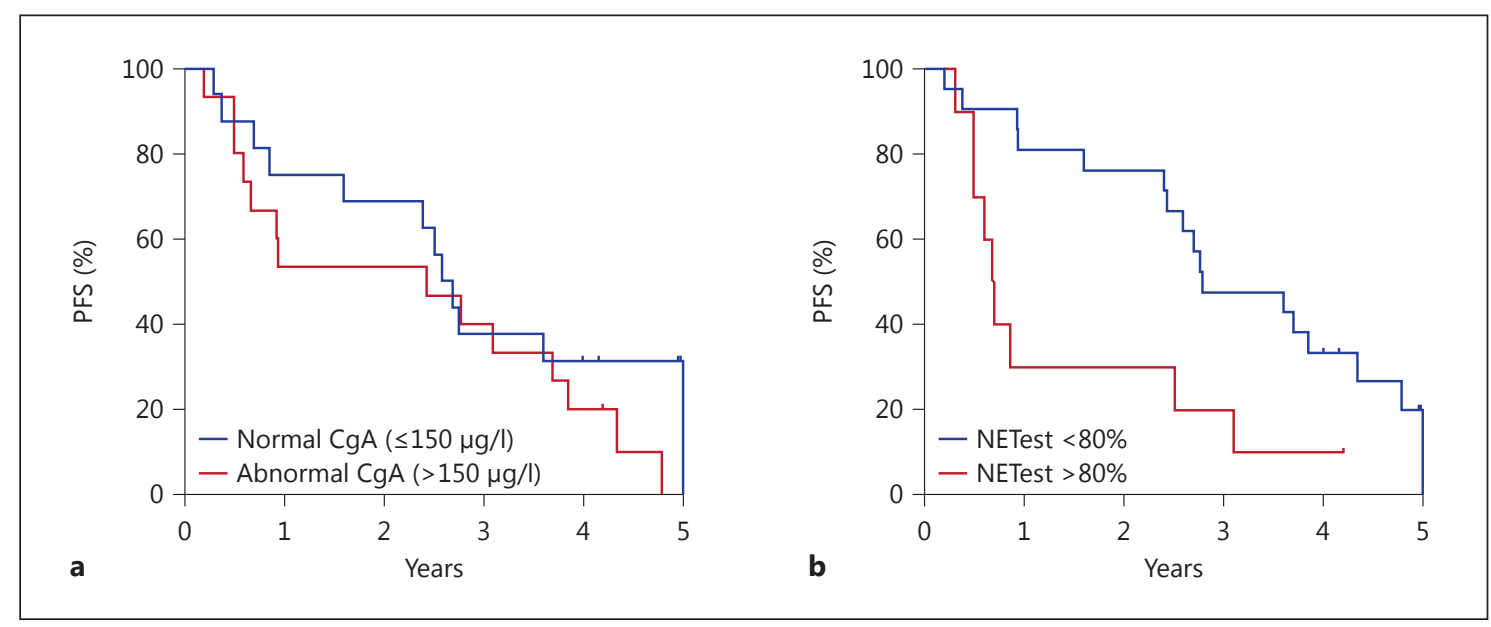

Fig. 3. Relationship between survival and baseline biomarker levels. a PFS was not associated with baseline CgA in this cohort; normal CgA levels $(\leq 150 \mu \mathrm{g} / \mathrm{l})$ were associated with a median survival of 2.65 years compared to 2.43 years in those with elevated $(>150$

NETest in the Patient Cohort $(\mathrm{n}=31)$

At baseline, the NETest was $51 \pm 5 \%$. Levels were significantly higher in the PD group (67.2 \pm 7.1 vs. $41.6 \pm$ $5.8 \%, \mathrm{p}<0.05$; fig. $2 \mathrm{~b}$ ). An elevated NETest (defined as $\geq 80 \%)$ was significantly associated $(\mathrm{p}=0.014)$ with the development of PD compared to lower NETest values (fig. $3 \mathrm{~b}$ ). The median survival was 0.68 years (NETest $\geq 80 \%$ ) compared to 2.78 years.

Analysis of the 7 patients (clinically stable at baseline) who had an intermediate or high NETest $(>40 \%)$ identified that all $7(100 \%)$ developed PD in a mean of 24 months (range: 3.6-57.5). Conversely, the 7 with stable disease, who never developed disease progression during the duration of the follow-up, all exhibited a low-activity $(\leq 40 \%)$ baseline NETest (mean follow-up: 52 months, range: $32-60.5$ months).

\section{Predictive Utility of Biomarkers $(n=31)$}

The study design allowed us to examine the predictive utility of the NETest compared to CgA at defined, clinically chosen, image-based follow-up times using multivariate and Kaplan-Meier analyses.

\section{Multivariate Analysis}

We initially investigated which baseline variables were associated with PFS. Cox proportional-hazard regression was fitted to the baseline data. Baseline $\mathrm{CgA}(\mu \mathrm{g} / \mathrm{l})$ and NETest (\%) levels as well as histological grade (grade 1 vs. 2) and site (gut vs. pancreas) were evaluated. The only significant covariate in the model was the NETest (hazard $\mu \mathrm{g} / \mathrm{l})$ levels $(\mathrm{p}=0.26)$. b NETest activity at baseline $(<80 \%)$ was associated with PFS of 2.78 years versus 0.68 years $(\mathrm{p}<0.02)$ in those with $>80 \%$. ratio, $\mathrm{HR}=1.022,95 \%$ confidence interval, $\mathrm{CI}=1.005$ $1.04, \mathrm{p}<0.012$ ). Neither grade (grade 1 vs. $2 ; \mathrm{HR}=1.095$, $95 \% \mathrm{CI}=0.473-2.54, \mathrm{p}=0.83)$ nor site $(\mathrm{HR}=0.72,95 \%$ $\mathrm{CI}=0.239-2.17, \mathrm{p}=0.56)$ or $\mathrm{CgA}(\mathrm{HR}=1.00,95 \% \mathrm{CI}=$ $1.00-1.00, \mathrm{p}=0.89$ ) were predictive of PFS in this cohort.

\section{Kaplan-Meier Analyses (T0 to First Restaging)}

The mean follow-up time from baseline to the first restaging scan was 194 days (range: 72-422). Assessments included: histological grade, NETest $(\geq 80 \%)$, normal versus elevated $(\geq 150 \mu \mathrm{g} / \mathrm{l}, \mathrm{n}=16)$ and abnormally elevated $\mathrm{CgA}(\geq 300 \mu \mathrm{g} / \mathrm{l}, \mathrm{n}=12)$. Values were assessed to predict disease progression at the initial restaging. $\mathrm{CgA}$ was not informative. The median survival with $\mathrm{CgA} \geq 150 \mu \mathrm{g} / \mathrm{l}$ was 335 days (vs. undefined for normal levels; fig. 4a), while it was 247 days in the 12 with $\mathrm{CgA} \geq 300 \mu \mathrm{g} / \mathrm{l}$ (fig. 4b). The only predictive biomarker was the NETest which exhibited a trend toward significance $(p=0.07)$ with outcome at this time point (fig. 4c, d). The HR for an elevated NETest was 3.3 (95\% CI $=0.78-14.3)$. The median survival was 247 days (not reached for NETest $\leq 79 \%$ ) after 422 days (fig. 4c). Lowering the NETest cutoff to $70 \%$ improved the HR to 3.5 ( $95 \% \mathrm{CI}=0.87-14.0$ ). The median survival remained 247 days (fig. $4 \mathrm{~d}$ ).

During the follow-up, 29 patients had a second blood sample (both NETest and CgA) and thereafter imagebased restaging. The mean time between blood measurement (T1) and restaging was 183 days (range: 26-814). $\mathrm{CgA}$ was not informative when either assessed in the entire cohort (normal levels vs. elevated levels, fig. 5a, me- 


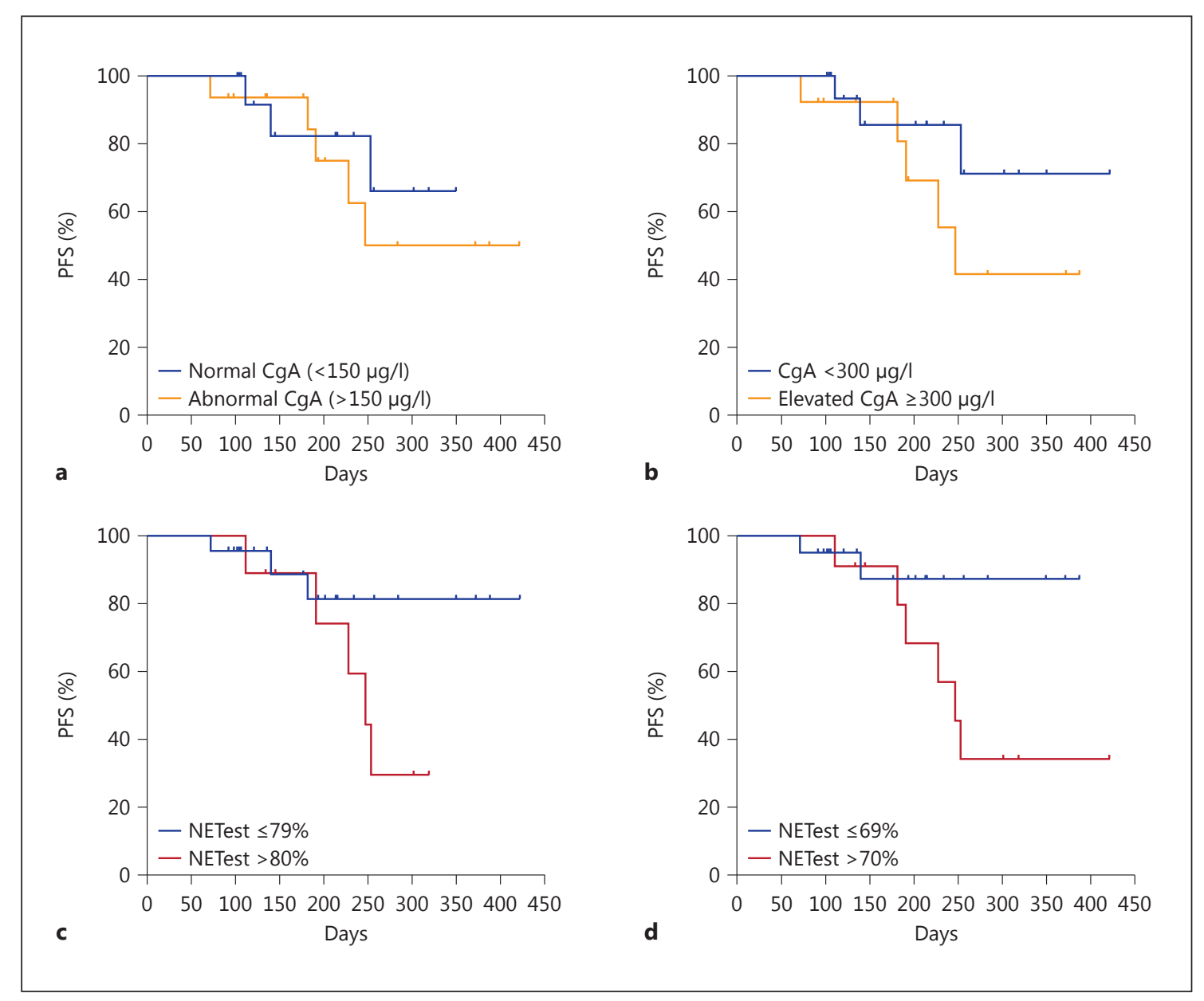

Fig. 4. Blood-based biomarkers and relationship with survival (baseline time point: T0, $\mathrm{n}=31$ ) assessed using Kaplan-Meier analysis. a PFS was not associated with elevated (>150 $\mu \mathrm{g} / \mathrm{l}) \mathrm{CgA}$ levels. b PFS was not linked to abnormally elevated $\mathrm{CgA}(\geq 300 \mu \mathrm{g} / \mathrm{l})$ at baseline in the 12 patients with elevated CgA. c PFS was associated

dian survival not reached in either cohort) or using 300 $\mu \mathrm{g} / \mathrm{l}$ (fig. $5 \mathrm{~b}$ ). In the latter, the median survival with an elevated CgA was undefined. Assessment of the NETest (using cutoffs of $\geq 70$ or $\geq 80 \%$ ) found that this was predictive (fig. $5 c, d)$. The HR for the NETest $(\geq 80 \%)$ was 5.5 (95\% CI $=0.77-38.9)$ with a median survival of 246 days (vs. not reached, $\mathrm{p}=0.07$; fig. $5 \mathrm{c}$ ). Using a cutoff of $70 \%$, the HR was 23.5 (95\% CI $=4.7-116.5$ ), and the median survival was 183 days (not reached for NETest $\leq 69 \%$, $p=$ 0.0009; fig. 5d).

The NETest was more informative than elevations in $\mathrm{CgA}$. NETest alterations (a rise to $\geq 80 \%$ in progressive disease or remaining low $(\leq 40 \%)$ in stable disease) occurred more consistently $(24 / 25$, i.e. $96 \%)$ than alterations in CgA (e.g. elevation $\geq 25 \%$ or no change in SD: with baseline NETest activity in this cohort; the median survival was 247 days in those with NETest $>80 \%(p=0.07)$. $\mathbf{d}$ PFS was associated with baseline NETest activity in this cohort; the median survival was 247 days in those with NETest $>70 \%(p=0.06)$.

$10 / 25$, i.e. $\left.40 \%, \mathrm{p}<2 \times 10^{-5}, \mathrm{x}^{2}=18.1\right)$. The time point at which the NETest $(\geq 80 \%)$ was measured prior to image evidence of $\mathrm{PD}$ was significantly earlier $(1.02 \pm 0.15$ years $)$ than for alterations in CgA ( $\Delta 25 \%: 0.51 \pm 0.11$ years, $\mathrm{p}=$ $0.034)$. Elevated CgA ( $\geq 300 \mu \mathrm{g} / \mathrm{l})$ occurred at $0.52 \pm 0.13$ years before indication of disease ( $\mathrm{p}=$ n.s. vs. $\operatorname{CgA} \Delta 25 \%)$. If a NETest $\geq 70 \%$ was used, the time point was even earlier. Progression was predicted $1.85 \pm 0.27$ years prior to image confirmation. This was significantly earlier than for either NETest $(\geq 80 \%, \mathrm{p}<0.02)$ or for CgA $(\Delta 25 \%$, $\mathrm{p}$ $=0.003$ ). Event curves for each of the biomarkers (fig. 6a, b) show that the median times prior to image-confirmed disease progression for $\mathrm{CgA}$ were 0.51 years $(\Delta 25 \%)$ and 0.60 years $(\geq 300 \mu \mathrm{g} / \mathrm{l})$, and for the NETest they were 0.76 years $(\geq 80 \%)$ and 1.62 years $(\geq 70 \%)$. 


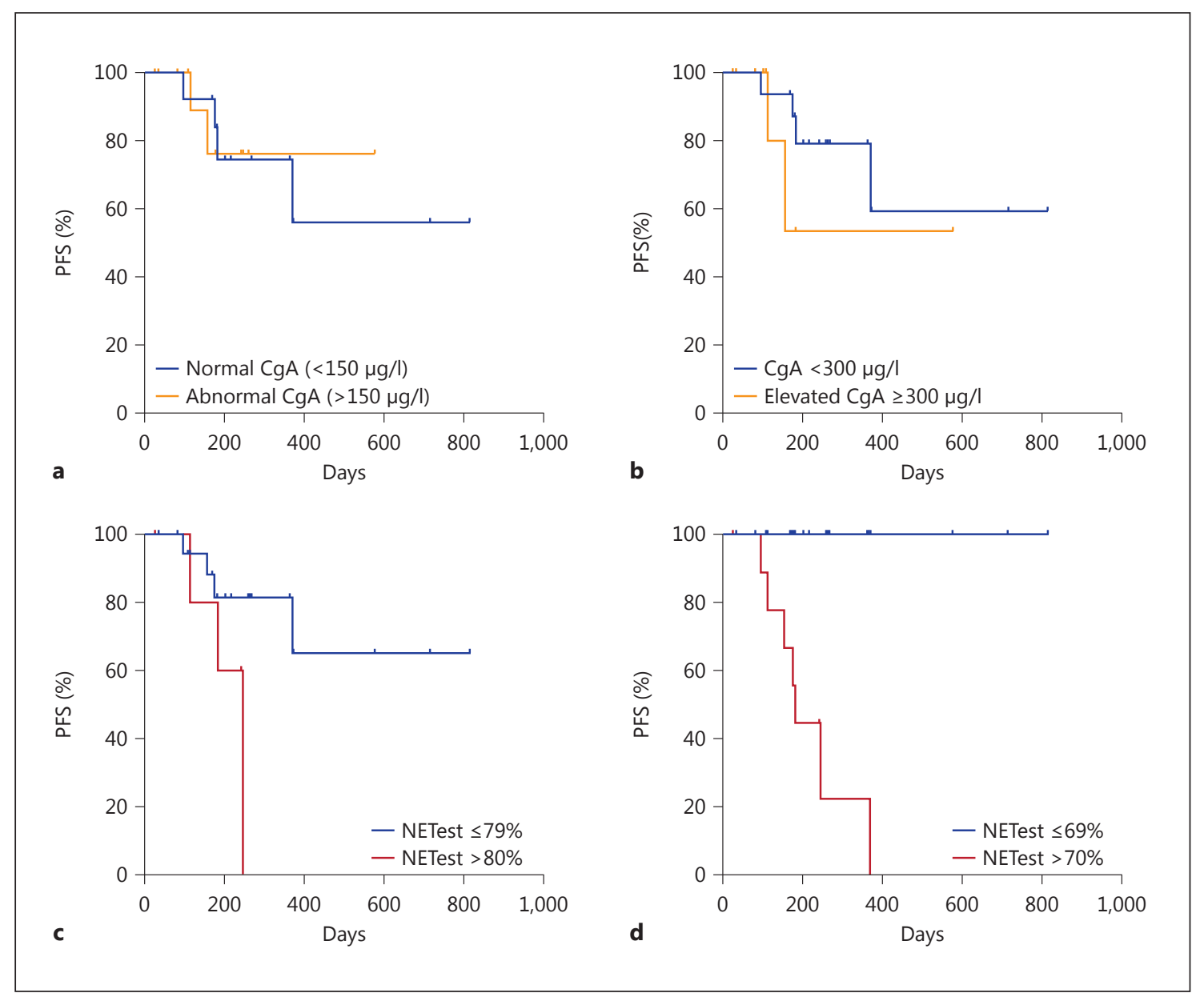

Fig. 5. Blood-based biomarkers and relationship with survival (second blood time point: T1, $\mathrm{n}=28$ ) assessed using Kaplan-Meier analysis. a PFS was not associated with elevated $(>150 \mu \mathrm{g} / \mathrm{l}) \mathrm{CgA}$ levels. b PFS was not linked to abnormally elevated CgA $(\geq 300$

\section{Discussion}

A critical unresolved issue in GEP-NET management is the early identification of disease progression [30]. Effective prognostic biomarkers are not robust, and imaging is relatively insensitive $[10,35]$. The current consensus is that an accurate circulating biomarker that captures the biological activity of a NET and predicts its clinical behavior would provide an optimal method for the early detection of disease progression [1]. We evaluated the role of a blood-based multigene transcript analysis as such a predictive and prognostic marker and assessed whether the performance was more effective than standard biomarkers providing added clinical utility.

RECIST criteria are the current default for defining therapeutic responses although their limitations are well $\mu \mathrm{g} / \mathrm{l})$ at the second blood time point (T1). c, d PFS was associated with baseline NETest activity in this cohort; the median survival was 246 days (cutoff $>80 \%$ ) or 183 days (cutoff $>70 \%$ ).

documented [8-10]. Local confounders such as necrosis, hemorrhaging or fibrosis complicate assessment [36] while the spatial resolution of CT/MRI $(\sim 2 \mathrm{~mm})$ approaches the limits of tumor measurement, particularly for recurrent or micrometastatic disease. This issue together with observer-dependent accuracy (low kappa) further confounds accuracy. Such difficulties are amplified by the often indolent growth rates of well- and moderately differentiated NETs.

Biomarkers such as $\mathrm{CgA}$ define tumor secretion and do not reflect biological activities including cell proliferation, growth factor signaling or any of the 'hallmarks of cancer' [37]. A variety of metrics have been assessed to evaluate the use of these markers. For example, a 30\% decrease in CgA (from pretreatment levels) is considered predictive of SSA efficacy [38], while an increase in three 


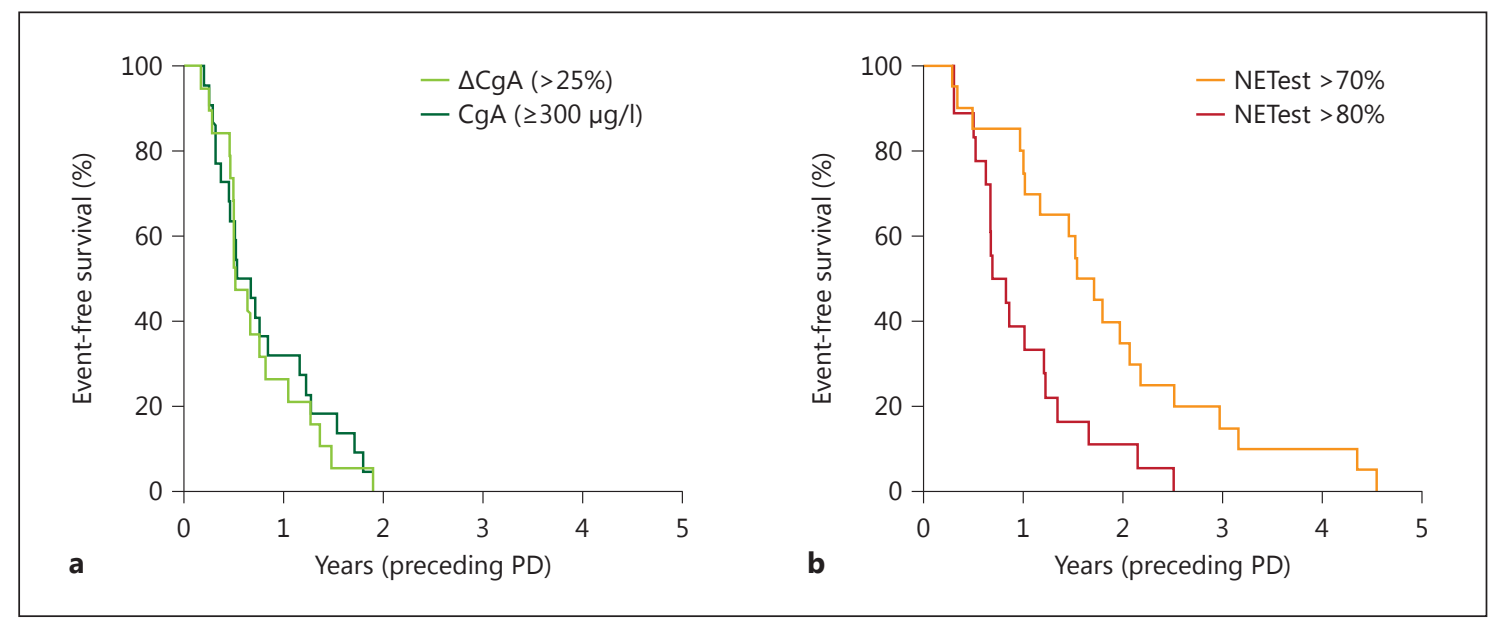

Fig. 6. Time before blood-based biomarker elevations preceded image-based evidence for PD. a Changes in $\mathrm{CgA}(\triangle \mathrm{CgA},>25 \%)$ occurred at a time point ( 0.51 years) similar to an elevated $\mathrm{CgA}$ $(\geq 300 \mu \mathrm{g} / \mathrm{l}$ : 0.60 years) prior to image-detected disease progression. Only $50 \%$ of patients (16 of 32 ) exhibited elevated CgA at baseline with a subset of 10 exhibiting abnormally elevated $(\geq 300$ $\mu \mathrm{g} / \mathrm{l}) \mathrm{CgA}$. b The median times prior to image-confirmed disease progression for the NETest were 0.76 years $(>80 \%)$ and 1.62 years $(>70 \%)$. All patients were NETest positive $(>14 \%)$. consecutive measurements is considered to anticipate relapse after midgut surgery [39]. Some authors proposed that alterations of $\geq 25 \%$ in $\mathrm{CgA}$ may have good sensitivities $(>75 \%)$ and specificities $(>85 \%)$ for predicting disease events [33] while others suggested that levels twice the ULN ( $300 \mu \mathrm{g} / \mathrm{l}$ or $300 \mathrm{ng} / \mathrm{ml})$ [32] or higher $(\geq 600)$ $[40]$ are effective predictors of disease progression. Irrespective of the cutoff levels proposed, numerous technical issues, e.g. low reproducibility and disease confounders (drugs, diseases), limit its utility. CgA and other single (mono)analyte biomarkers have not met the expectations of the clinical community $[19,41,42]$.

Investigation has focused on the development of multianalyte assays that can identify multiple key elements of neoplastic cell function and be interfaced with sophisticated mathematical models (multianalyte algorithm analysis). This approach has been acknowledged as necessary to define and predict the exquisite complexity of the neoplastic conundrum [43]. Defining the bandwidth of the genomic regulation of neoplasia requires the simultaneous assessment of numerous parameters that circumscribe diverse aspects of tumor biology and facilitate the 'framing' of clinical behavior [44-46]. Numerous successful applications of this principle have advanced the disease management of neoplasia in other sites including breast, liver, colon, prostate and lung cancer [44, 47-50].

Multianalyte algorithm analysis strategies based upon a 51-gene signature (NETest) have been reported in NETs $[24,26,28,29,51-53]$. This defines the circulating NET 'fingerprint' [54] and exhibits a higher sensitivity and specificity (98 and 97\%, respectively) than secretory markers for identifying neoplasia $[25,51]$. The assay is standardized and highly reproducible (inter- and intraassay coefficient of variation $<2 \%$ ), and is independent of tumor heterogeneity [28]. Gene expression is captured in a $0-8$ score derived from 4 different prediction algorithms that is mathematically scaled to disease activity $(0-100 \%)$ by interpolating the expression of 'omic' transcripts that define specific biological components (hallmarks) of neoplasia [27]. HR-derived analyses enable the derivation of scores that define disease activity $(0-14 \%$, minimal activity; $14-40 \%$, low activity; $>40 \%$, intermediate and high activity) [26]. Individual activity levels correlate accurately with clinically stable disease or PD and effectively facilitate the determination of treatment efficacy [26].

In the current study, all patients were NETest positive, e.g. $\geq 14 \%$ at baseline. NETest levels were significantly $(\mathrm{p}<0.05)$ elevated in $8(90 \%)$ of the 9 patients identified with PD. One patient (terminal ileum, grade 1) had a score of $20 \%$, and was termed as 'mixed' progression, suggesting the low score reflected a response to therapy (SSA). An analysis of the 7 (defined as clinically stable at baseline) who did not have a low tumor activity NETest (i.e. scores $>40 \%$ ) showed that all developed PD with a mean of 24 months (range: 3.6-57.5 months). Conversely, 7 stable (at baseline) patients who never developed disease progression exhibited a low-activity $(<40 \%)$ NETest 
(mean follow-up: 52 months, range: 32-60.5 months). While this shows some discordance between the NETest and imaging at a particular point in time (50\% of patients had low activity, 50\% high activity despite all 14 exhibiting disease 'stability'), the NETest accurately (100\%) predicted outcome. This is predictable given the limitations of imagery in terms of sensitivity and defining biological activity. An image cannot intrinsically provide dynamic information about tumor activity whereas a circulating molecular fingerprint that defines neoplastic biology is specifically designed to identify and quantify such information. These data suggest that the use of blood-based tumor-derived molecular information in conjunction with standard imaging may provide added clinical value in defining disease status and guiding therapy.

Three patients (No. 15, 21, and 26) are worthy of consideration. All were surgically cured ('complete resection') at operation. They comprised 2 low-grade (Ki-67<1\%) duodenal NETs (one, patient 15, was a gastrinoma) and a pancreatic tumor. Two of the 3 'surgically cured' individuals (No. 15 and 21) did not exhibit 'clinical' evidence of disease (by CT/MRI) for the duration of the study. Their NETest scores at baseline (after surgery) were 27 and 20\%, respectively. Two sequential measurements at 2.6 and 3.9 years in patient 15 were 33 and 33\%, respectively; for patient 21, the NETest at 3.2 years was $20 \%$. These fall into the 'low-activity' range. In a separate 5-year follow-up study of a surgical cohort $(\mathrm{n}=12$; all with NET grade 1 , none with gastrinoma), complete resection was associated with NETest levels $<14 \%$ [52]. The elevated postsurgical level in the duodenal gastrinoma patient (33\%) in the current study is of concern and may reflect microscopic disease not identifiable at imaging. Low-activity, image-negative disease is suggested by the follow-up circulating values (33\%). One patient, No. 26, with no disease at baseline, developed recurrence after 2.2 years. This was a grade 3 $(\mathrm{Ki}-67=30 \%)$ pancreatic NET. The NETest was $14 \%$ at baseline, and CgA levels were normal. Thereafter, NETest levels increased (score $>65 \%$ ) while $\mathrm{CgA}$ remained normal. The borderline score (14\%) after surgery suggests that the completeness of surgical excision might require re-evaluation. The subsequent rise demonstrates that the tumor recurred. The elevation in the NETest was concordant with disease recurrence and importantly occurred $\sim 6$ months before any measureable elevation in CgA.

Cox proportional-hazard modeling identified that of all variables assessed, only the NETest was predictive of PFS. The HR was 1.022 demonstrating that for each percentage point change (increase) in the NETest, the risk of disease progression was $2.2 \%$. NETest values for $>70$ or
$>80 \%$ would therefore have HRs of $\sim 2.5$ and $\sim 2.8$, respectively. In this model, baseline $\mathrm{CgA}(\mathrm{HR}=1)$ and site $(\mathrm{HR}=0.72)$ were not associated with PFS. In addition, histological grade was not a significant variable either $(\mathrm{HR}=1.095)$. The low numbers $(\mathrm{n}=31)$ likely contribute to the absence of statistical significance; however, despite this, the NETest was mathematically identified as being significant even in this cohort.

We also performed Kaplan-Meier PFS analysis which identified that the NETest ( $\geq 80$ or $\geq 70 \%$ ) at baseline (T0) exhibited a trend toward significance $(\mathrm{p}=0.06)$ with predicting outcome (RECIST-based assessment after a mean of $\sim 6$ months). Proof of principle for the NETest as a prognostic was confirmed by clinical assessment after a second blood sample. The mean time to the second image assessment was also 6 months. In this cohort $(\mathrm{n}=29)$, the NETest $(\geq 80 \%)$ was associated with a median survival of 246 days (vs. not reached for NETest $\leq 79 \%$ ). Decreasing the cutoff to $70 \%$ resulted in an HR of 25.7 (95\% CI = 5.2-129). The median survival was 183 days (not reached for NETest $\leq 69 \%, \mathrm{p}<0.00001$ ). These analyses (Cox/ Kaplan-Meier) show that NETest levels are a significant prognostic variable in GEP-NETs (independent of grade and site) and can accurately predict clinical outcome as well as response to therapy.

$\mathrm{CgA}$, in contrast to the NETest and consistent with its function as a unidimensional measure of secretion, was not an effective biomarker. Firstly, it was not identified in the Cox proportional-hazard model as an informative variable. Secondly, elevated levels, i.e. $>1 \times \mathrm{ULN}$, were only noted in $50 \%$ of patients at baseline, thus half the patients could $a b$ initio derive no value from its assessment. This is confirmed by multivariable analysis. Moreover, the 2 'surgically cured' patients (no evidence of disease recurrence) had elevated baseline levels, $343 \mu \mathrm{g} / \mathrm{l}$ (patient 15) and 381 $\mu \mathrm{g} / \mathrm{l}$ (patient 21), respectively. Subsequent measurements showed that $\mathrm{CgA}$ was only normalized in patient 21 . Patient 15, who had a gastrinoma, had elevated levels consistent with the secretory behavior captured by this biomarker. Baseline CgA was not statistically significantly elevated in the PD cohort. A subanalysis of the 16 with elevated baseline found that abnormally high $(2 \times \mathrm{ULN})$ levels $(\geq 300 \mu \mathrm{g} / \mathrm{l})$ were not associated with outcome. KaplanMeier analysis did not identify any significant role for $\mathrm{CgA}$ as a prognostic marker in this cohort either. Use of higher cutoffs, e.g. $\geq 600 \mu \mathrm{g} / \mathrm{l}$, was also noninformative.

In head-to-head comparisons, the NETest was significantly more informative than alterations in CgA. Assessment of NETest alterations (elevation to levels $\geq 80 \%$ in PD or remaining low, i.e. $<47 \%$, in stable disease) oc- 
curred more consistently (96\%) than alterations in CgA (e.g. elevation $\geq 25 \%, p<2 \times 10^{-5}$ ). This should be considered in the context that in $50 \%$ of patients, CgA was never elevated despite a histological NET diagnosis. Of considerable relevance was the observation that elevations in NETest $(\geq 80 \%)$ occurred at a significantly earlier time point than image evidence of PD. Such changes occurred $\sim 1 \pm 0.15$ years before image confirmation of disease, time points similar to that identified for circulating DNA in colorectal cancer (mean $=10$ months) [55]. More germane to the early identification of disease progress was the observation that if the cutoff was adjusted downward to $\geq 70 \%$, the time point of identification of disease progression was significantly earlier. A NET level of $\geq 70 \%$ enabled identification of disease progression $\sim 2$ years prior to evidence of image-identifiable disease progression. This was significantly earlier than for a $\geq 80 \%$ cutoff $(\mathrm{p}<0.02)$. In contrast, alterations in CgA were less informative. A change of $25 \%$ or any elevation $\geq 300 \mu \mathrm{g} / \mathrm{l}$ occurred only $\sim 0.5$ years prior to image-based confirmation and was unidentifiable in $50 \%$.

These data are consistent with the proposal that the NETest had a prognostic role in this cohort and confirms utility in clinical management as has been previously noted [29]. High levels are associated with disease progression while low levels reflect and predict disease stability. Limitations of the study include the relatively small numbers (34 patients, the final analyzed cohort included 31 patients), that this was not a formal prospective study in a homogenously treated cohort (blood sampling was undertaken on average 2.5/patient and restaging on average $\sim 7$ occasions/patient) and that some of the data were extracted and confirmed retrospectively (e.g. imaging was re-evaluated according to RECIST, some CgA samples were measured retrospectively). The study strengths in- clude that it was undertaken at an ENETS Center of Excellence (Charité, Berlin) in a 'real-world' setting with state-of-the-art imaging (single center), follow-up and patient care using standardized biomarker assessments. The concordance in the results between two different statistical approaches, Cox proportional-hazard regression and Kaplan-Meier assessment, substantiate the utility of the NETest as a biomarker. The data further define the increasing awareness of the limitations of CgA measurements.

In conclusion, the NETest is an independent variable predictive of clinical disease status. The measurement of this circulating transcript signature correlates with clinical disease status, and levels ( $\geq 70 \%)$ are prognostic for welldifferentiated GEP-NET progression (per RECIST). The NETest $<40 \%$ correlated with disease stability over $\sim 5$ years, identifying this molecular signature also as predictive. Patients clinically categorized as stable with high NETest levels ( $\geq 70 \%$ ) develop disease progression in $100 \%$ of cases within 2 years. The overall utility is emphasized by observations that clinically actionable alterations occurred $\sim 1$ year before image-based evidence of disease progression. Unlike single analyte secretory measurements, the NETest accurately defines the spectrum of well-differentiated GEP-NET disease and, more critically, can predict when disease stability evolves into progression.

\section{Acknowledgments}

We thank Ines Eichorn for sample acquisition. The study was supported by Clifton Life Sciences.

\section{Disclosure Statement}

There is no conflict of interest.
References
1 Oberg K, Modlin I, DeHerder W, Pavel M, Klimstra D, Frilling A, Metz D, Heaney A, Kwekkeboom D, Strosberg J, Meyer T, Moss S, Washington M, Wolin E, Liu E, Goldenring $\mathrm{J}$ : Biomarkers for neuroendocrine tumor disease: a delphic consensus assessment of multianalytes, genomics, circulating cells and monoanalytes. Lancet Oncol 2015; 16:e435046.

-2 Pape UF, Perren A, Niederle B, Gross D, Gress T, Costa F, Arnold R, Denecke T, Plockinger U, Salazar R, Grossman A: ENETS consensus guidelines for the management of patients with neuroendocrine neoplasms from the jejuno-ileum and the appendix including goblet cell carcinomas. Neuroendocrinology 2012;95:135-156

\footnotetext{
3 Pavel M, Baudin E, Couvelard A, Krenning E, Oberg K, Steinmuller T, Anlauf M, Wiedenmann B, Salazar R: ENETS consensus guidelines for the management of patients with liver and other distant metastases from neuroendocrine neoplasms of foregut, midgut, hindgut, and unknown primary. Neuroendocrinology 2012;95:157-176.

4 Frilling A, Modlin I, Kidd M, Russell C, Breitenstein S, Salem R, Kwekkeboom D, Lau W-Y, Klersy C, Vilgrain V, Davidson B, Siegler M, Caplin M, Solcia E, Schilsky RL, Working Group on Neuroendocrine Liver Metastases: Recommendations for management of patients with neuroendocrine liver metastases. Lancet Oncol 2014;15:e8-e21.
} 
5 Modlin IM, Moss SF, Chung DC, Jensen RT, Snyderwine E: Priorities for improving the management of gastroenteropancreatic neuroendocrine tumors. J Natl Cancer Inst 2008; 100:1282-1289.

-6 Lewis MA, Yao JC: Molecular pathology and genetics of gastrointestinal neuroendocrine tumours. Curr Opin Endocrinol Diabetes Obes 2013;4:4.

7 De Mestier L, Dromain C, d'Assignies G, Scoazec JY, Lassau N, Lebtahi R, Brixi H, Mitry E, Guimbaud R, Courbon F, d'Herbomez M, Cadiot G: Evaluating neuroendocrine tumor progression and therapeutic responses in the era of targeted therapies: state of the art. Endocr Relat Cancer 2014;21:R105-R120.

$\checkmark 8$ Eisenhauer EA, Therasse P, Bogaerts J, Schwartz LH, Sargent D, Ford R, Dancey J, Arbuck S, Gwyther S, Mooney M, Rubinstein L, Shankar L, Dodd L, Kaplan R, Lacombe D, Verweij J: New response evaluation criteria in solid tumours: revised RECIST guideline (version 1.1). Eur J Cancer 2009;45:228-247.

\$ Neperud J, Mahvash A, Garg N, Murthy R, Szklaruk J: Can imaging patterns of neuroendocrine hepatic metastases predict response yttrium-90 radioembolotherapy? World J Radiol 2013;5:241-247.

10 Denecke T, Baur AD, Ihm C, Steffen IG, Tischer E, Arsenic R, Pascher A, Wiedenmann B, Pavel M: Evaluation of radiological prognostic factors of hepatic metastases in patients with non-functional pancreatic neuroendocrine tumors. Eur J Radiol 2013;82:e550555.

11 Toumpanakis C, Kim MK, Rinke A, Bergestuen DS, Thirlwell C, Khan MS, Salazar R, Oberg K: Combination of cross-sectional and molecular imaging studies in the localization of gastroenteropancreatic neuroendocrine tumors. Neuroendocrinology 2014;21:21.

$\checkmark 12$ Ruf J, Schiefer J, Kropf S, Furth C, Ulrich G, Kosiek O, Denecke T, Pavel M, Pascher A, Wiedenmann B, Amthauer H: Quantification in (68)Ga-DOTA(0)-Phe(1)-Tyr(3)-octreotide positron emission tomography/computed tomography: can we be impartial about partial volume effects? Neuroendocrinology 2013;97:369-374.

13 Virgolini I, Ambrosini V, Bomanji JB, Baum RP, Fanti S, Gabriel M, Papathanasiou ND, Pepe G, Oyen W, De Cristoforo C, Chiti A: Procedure guidelines for PET/CT tumour imaging with ${ }^{68} \mathrm{Ga}$-DOTA-conjugated peptides: ${ }^{68} \mathrm{Ga}$-DOTA-TOC, ${ }^{68} \mathrm{Ga}$-DOTA-NOC, ${ }^{68} \mathrm{Ga}$ DOTA-TATE. Eur J Nucl Med Mol Imaging 2010;37:2004-2010.

14 Binderup T, Knigge U, Loft A, Federspiel B, Kjaer A: ${ }^{18} \mathrm{~F}$-fluorodeoxyglucose positron emission tomography predicts survival of patients with neuroendocrine tumors. Clin Cancer Res 2010;16:978-985.

15 Castano JP, Sundin A, Maecke HR, Villabona C, Vazquez-Albertino R, Navarro E, Oberg K: Gastrointestinal neuroendocrine tumors (NETs): new diagnostic and therapeutic challenges. Cancer Metastasis Rev 2014;5:5.
16 Faivre S, Ronot M, Dreyer C, Serrate C, Hentic O, Bouattour M, Bruno O, Couvelard A, Vilgrain $\mathrm{V}$, Raymond $\mathrm{E}$ : Imaging response in neuroendocrine tumors treated with targeted therapies: the experience of sunitinib. Target Oncol 2012;7:127-133.

17 Biomarkers on a roll. Nat Biotechnol 2010;28: 431.

18 Modlin I, Kidd M, Taylor A, Drozdov I, Bodei L: Neuroendocrine tumor biomarkers: current status and perspectives. Neuroendocrinology 2014;100:265-277.

19 Marotta V, Nuzzo V, Ferrara T, Zuccoli A, Masone M, Nocerino L, Del Prete M, Marciello F, Ramundo V, Lombardi G, Vitale M, Colao A, Faggiano A: Limitations of chromogranin A in clinical practice. Biomarkers 2012;17:186-191.

20 Mason CE, Porter SG, Smith TM: Characterizing multi-omic data in systems biology. Adv Exp Med Biol 2014;799:15-38.

21 Izmailov R, Guest PC, Bahn S, Schwarz E: Algorithm development for diagnostic biomarker assays. Int Rev Neurobiol 2011;101: 279-298.

22 Hodgkinson CL, Morrow CJ, Li Y, Metcalf RL, Rothwell DG, Trapani F, Polanski R, Burt DJ, Simpson KL, Morris K, Pepper SD, Nonaka D, Greystoke A, Kelly P, Bola B, Krebs MG, Antonello J, Ayub M, Faulkner S, Priest L, Carter L, Tate C, Miller CJ, Blackhall F, Brady G, Dive C: Tumorigenicity and genetic profiling of circulating tumor cells in smallcell lung cancer. Nat Med 2014;20:897-903.

-23 Li SC, Essaghir A, Martijn C, Lloyd RV, Demoulin JB, Oberg K, Giandomenico V: Global microRNA profiling of well-differentiated small intestinal neuroendocrine tumors. Mod Pathol 2013;26:685-696.

24 Modlin I, Drozdov I, Kidd M: The identification of gut neuroendocrine tumor disease by multiple synchronous transcript analysis in blood. PLoS One 2013;8:e63364.

25 Modlin I, Drozdov I, Alaimo D, Callahan S, Teixeira N, Bodei L, Kidd M: A multianalyte PCR blood test outperforms single analyte ELISAs for neuroendocrine tumor detection. Endocr Relat Cancer 2014;21:615-628.

26 Kidd M, Drozdov I, Modlin I: Blood and tissue neuroendocrine tumor gene cluster analysis correlate, define hallmarks and predict disease status. Endocr Relat Cancer 2015;22: 561-575.

27 Walenkamp A, Crespo G, Fierro Maya F, Fossmark R, Igaz P, Rinke A, Tamagno G, Vitale G, Oberg K, Meyer T: Hallmarks of gastrointestinal neuroendocrine tumours: implications for treatment. Endocr Relat Cancer 2014;21:R445-R460.

28 Modlin I, Drozdov I, Kidd M: Gut neuroendocrine tumor blood qPCR fingerprint assay: characteristics and reproducibility. Clin Chem 2014;52:419-429.
Cwikla JB, Bodei L, Kolasinska-Cwikla A, Sankowski A, Modlin IM, Kidd M: Circulating transcript analysis (NETest) in GEPNETs treated with somatostatin analogs defines therapy. J Clin Endocrinol Metab 2015; 100:E1437-E1445.

30 Frey BJ, Dueck D: Clustering by passing messages between data points. Science 2007;315: 972-976.

31 Dilz LM, Denecke T, Steffen IG, Prasad V, von Weikersthal LF, Pape UF, Wiedenmann B, Pavel M: Streptozocin/5-fluorouracil chemotherapy is associated with durable response in patients with advanced pancreatic neuroendocrine tumours. Eur J Cancer 2015; 51:1253-1262.

32 Ter-Minassian M, Chan JA, Hooshmand SM, Brais LK, Daskalova A, Heafield R, Buchanan L, Qian ZR, Fuchs CS, Lin X, Christiani DC, Kulke MH: Clinical presentation, recurrence, and survival in patients with neuroendocrine tumors: results from a prospective institutional database. Endocr Relat Cancer 2013;20: 187-196.

- 33 Jensen KH, Hilsted L, Jensen C, Mynster T, Rehfeld JF, Knigge U: Chromogranin A is a sensitive marker of progression or regression in ileo-cecal neuroendocrine tumors. Scand J Gastroenterol 2013;48:70-77.

34 Bosman FT: WHO Classification of Tumours of the Digestive System, ed 4. Lyon, IARC Press, 2010

-35 Baur AD, Pavel M, Prasad V, Denecke T: Diagnostic imaging of pancreatic neuroendocrine neoplasms (pNEN): tumor detection, staging, prognosis, and response to treatment. Acta Radiol 2016;57:260-270.

36 Bodei L, Kidd M, Prasad V, Baum RP, Drozdov I, Modlin IM: The future of nuclear medicine imaging of neuroendocrine tumors: on a clear day one might see forever... Eur J Nucl Med Mol Imaging 2014;41:2189-2193.

- 37 Hanahan D, Weinberg RA: Hallmarks of cancer: the next generation. Cell 2011;144:646674.

38 Massironi S, Conte D, Sciola V, Spampatti MP, Ciafardini C, Valenti L, Rossi RE, Peracchi M: Plasma chromogranin A response to octreotide test: prognostic value for clinical outcome in endocrine digestive tumors. Am J Gastroenterol 2010;105:2072-2078.

39 Massironi S, Rossi RE, Casazza G, Conte D, Ciafardini C, Galeazzi M, Peracchi M: Chromogranin $\mathrm{A}$ in diagnosing and monitoring patients with gastroenteropancreatic neuroendocrine neoplasms: a large series from a single institution. Neuroendocrinology 2014; 100:240-249.

40 Sabet A, Dautzenberg K, Haslerud T, Aouf A, Sabet A, Simon B, Mayer K, Biersack HJ, Ezziddin S: Specific efficacy of peptide receptor radionuclide therapy with (177)Lu-octreotate in advanced neuroendocrine tumours of the small intestine. Eur J Nucl Med Mol Imaging 2015;42:1238-1246. 
41 Marotta V, Nuzzo V, Ferrara T, Zuccoli A, Masone M, Nocerino L, Del Prete M, Marciello F, Ramundo V, Lombardi G, Vitale M, Colao A, Faggiano A: Limitations of chromogranin A in clinical practice. Biomarkers 2012;17:186-191.

-42 Kulke MH, Siu LL, Tepper JE, Fisher G, Jaffe D, Haller DG, Ellis LM, Benedetti JK, Bergsland EK, Hobday TJ, Van Cutsem E, Pingpank J, Oberg K, Cohen SJ, Posner MC, Yao JC: Future directions in the treatment of neuroendocrine tumors: consensus report of the National Cancer Institute neuroendocrine tumor clinical trials planning meeting. J Clin Oncol 2011;29:934-943.

-43 Kristensen VN, Lingjaerde OC, Russnes HG, Vollan HK, Frigessi A, Borresen-Dale AL: Principles and methods of integrative genomic analyses in cancer. Nat Rev Cancer 2014;14: 299-313.

44 Exner R, Bago-Horvath Z, Bartsch R, Mittlboeck M, Retel VP, Fitzal F, Rudas M, Singer C, Pfeiler G, Gnant M, Jakesz R, Dubsky P: The multigene signature MammaPrint impacts on multidisciplinary team decisions in ER+, HER2- early breast cancer. Br J Cancer 2014;111:837-842.

45 Marshall KW, Mohr S, Khettabi FE, Nossova N, Chao S, Bao W, Ma J, Li XJ, Liew CC: A blood-based biomarker panel for stratifying current risk for colorectal cancer. Int J Cancer 2010;126:1177-1186
46 Ginde S, Hohenwalter MD, Foley WD, Sowinski J, Bartz PJ, Venkatapuram S, Weinberg C, Tweddell JS, Earing MG: Noninvasive assessment of liver fibrosis in adult patients following the Fontan procedure. Congenit Heart Dis 2012;7:235-242.

47 Urgard E, Vooder T, Vosa U, Valk K, Liu M, Luo C, Hoti F, Roosipuu R, Annilo T, Laine J, Frenz CM, Zhang L, Metspalu A: Metagenes associated with survival in non-small cell lung cancer. Cancer Inform 2011;10:175-183.

48 Patel K, Friedrich-Rust M, Lurie Y, Grigorescu M, Stanciu C, Lee CM, Schiff ER, Haussinger D, Manns MP, Gerken G, Colle I, Torbenson M, Pulkstenis E, Subramanian GM, McHutchison JG, Zeuzem S: Fibrosure and fibroscan in relation to treatment response in chronic hepatitis C virus. World J Gastroenterol 2011;17:4581-4589.

-49 Marisa L, de Reynies A, Duval A, Selves J, Gaub MP, Vescovo L, Etienne-Grimaldi MC, Schiappa R, Guenot D, Ayadi M, Kirzin S, Chazal M, Flejou JF, Benchimol D, Berger A, Lagarde A, Pencreach E, Piard F, Elias D, Parc Y, Olschwang S, Milano G, Laurent-Puig P, Boige V: Gene expression classification of colon cancer into molecular subtypes: characterization, validation, and prognostic value. PLoS Med 2013;10:e1001453.

50 Danila DC, Anand A, Schultz N, Heller G, Wan M, Sung CC, Dai C, Khanin R, Fleisher M, Lilja H, Scher HI: Analytic and clinical validation of a prostate cancer-enhanced messenger RNA detection assay in whole blood as a prognostic biomarker for survival. Eur Urol 2014;65:1191-1197.
51 Modlin IM, Kidd M, Bodei L, Drozdov I, Aslanian $\mathrm{H}$ : The clinical utility of a novel bloodbased multi-transcriptome assay for the diagnosis of neuroendocrine tumors of the gastrointestinal tract. Am J Gastroenterol 2015;110: 1223-1232.

52 Modlin I, Frilling A, Salem R, Alaimo D, Drymousis $\mathrm{P}$, Wasan $\mathrm{H}$, Callahan S, Faiz O, Weng L, Teixeira N, Bodei L, Drozdov I, Kidd M: Blood measurement of neuroendocrine gene transcripts defines the effectiveness of surgical resection and ablation strategies. Surgery 2016;159:336-347.

53 Bodei L, Kidd M, Modlin IM, Prasad V, Severi S, Ambrosini V, Kwekkeboom DJ, Krenning EP, Baum RP, Paganelli G, Drozdov I: Gene transcript analysis blood values correlate with (68)Ga-DOTA-somatostatin analog (SSA) PET/CT imaging in neuroendocrine tumors and can define disease status. Eur J Nucl Med Mol Imaging 2015;42:1341-1352.

54 Modlin I, Drozdov I, Kidd M: A multitranscript blood neuroendocrine tumor molecular signature to identify treatment efficacy and disease progress. J Clin Oncol 2013; 31(suppl):A4137.

55 Reinert T, Scholer LV, Thomsen R, Tobiasen $\mathrm{H}$, Vang S, Nordentoft I, Lamy P, Kannerup AS, Mortensen FV, Stribolt K, Hamilton-Dutoit S, Nielsen HJ, Laurberg S, Pallisgaard N, Pedersen JS, Orntoft TF, Andersen CL: Analysis of circulating tumour DNA to monitor disease burden following colorectal cancer surgery. Gut 2016;65:625-634. 